\title{
PERCEPÇÃO DE ADOLESCENTES SOBRE UMA AÇÃO EDUCATIVA EM ORIENTAÇÃO SEXUAL REALIZADA POR ACADÊMICOS(AS) DE ENFERMAGEM
}

\author{
Perception of adolescents about an educative action in sexual \\ orientation conducted by nursing academics'. \\ Percepción de los adolescentes sobre una acción educativa \\ realizada por academicos de enfermeria
}

\section{RESUMO}

Trata-se de um estudo descritivo-exploratório, com abordagem qualitativa, que objetivou conhecer a percepção de adolescentes acerca das ações de orientação sexual realizadas em uma escola pública do interior do Rio Grande do Sul e identificar fragilidades e potencialidades das ações. Foram informantes 15 estudantes do ensino médio, com idade entre 15 e 17 anos. Os dados foram coletados em agosto de 2008 por meio de entrevistas e tratados pela análise de conteúdo temática. Foi possível identificar que os adolescentes aprovaram esse tipo de trabalho, e a maioria relatou a importância para a sua vida, principalmente devido à ausência de dialogo com a família. Identificaram-se potencialidades do projeto, como o uso de metodologia participativa, que é capaz de promover um clima de trabalho acolhedor e produtivo, proporcionando maior envolvimento e aprendizado.

Palavras-chave: Adolescente. Sexualidade. Educação Sexual

\begin{abstract}
That is an exploratory and descriptive study with qualitative approach, which aimed to find the perception of adolescents on the sexual orientation actions in a public school from the inner of Rio Grande do Sul and to identify the actions' fragilities and potentials. Fifteen high school students, at the age of 15 to 17 years were the informers of this research. Data were collected in August of 2008 by interviews and they were observed by the thematic content analysis. It was possible to find that students approve this kind of work because the most part of them related the importance it has in their lives, mainly due to the absence of dialog with the family. Potentials of the project were found, as the use of participative methodology which is able to promote a climate of homelike and productive work, providing larger involvement and learning.
\end{abstract}

Keywords: Adolescent. Sexuality. Sex education.

\section{Resumen}

Este es un estudio descriptivo-exploratorio con enfoque cualitativo, que tiene por objetivo conocer la percepción de los adolescentes acerca de las acciones de orientación sexual realizadas en una escuela pública en el interior del Rio Grande do Sul y identificar las fragilidades y potencialidades de las acciones. Los informantes fueron 15 estudiantes de la enseñanza secundaria de edades comprendidas entre los 15 y 17 años. Los datos fueron colectados en agosto de 2008 a través de entrevistas y tratado por el análisis de contenido temático. Fue posible identificar que los(as) adolescentes aprobarán esta manera de trabajo y la mayoría relató la importancia para su vida, principalmente debido a la falta de diálogo con la familia. Se identificaron potenciales del proyecto, tales como la utilización de la metodología participativa, que es capaz de promover un ambiente de trabajo cordial y productivo, proporcionando mayor participación y aprendizaje.

Palabras clave: Adolescentes. Sexualidad. Educación sexual

\footnotetext{
'Enfermeira. Doutora em Enfermagem. Professora Adjunta da Escola de Enfermagem da FURG. Líder do Grupo de Estudos e Pesquisas sobre Enfermagem, Gênero e Sociedade - GEPEGS e Diretora da Escola de Enfermagem. Brasil. E-mail: adriana@vetorial.net,'²nfermeira. Doutora em Enfermagem. Professora Titular da Escola de Enfermagem da FURG. Líder do Grupo de Estudos e Pesquisas sobre Enfermagem, Gênero e Sociedade - GEPEGS. Brasil. E-mail: vlogomes@terra.com.br, ${ }^{3}$ Enfermeira Residente do primeiro ano do Programa de Residência integrada em Saúde do Grupo Hospitalar Conceição - GHC. Brasil. E-mail: karinacteixeira@terra.com.br
} 


\section{INTRODUÇÃO}

A adolescência é uma fase de transição gradual da infância para a idade adulta, que vem sendo cada vez mais estudada por profissionais que se dedicam ao atendimento de jovens na faixa etária de 10 a 19 anos. ' É uma etapa crucial do processo de crescimento e desenvolvimento humano, que se manifesta por intensas, bruscas e marcantes transformações anatômicas, fisiológicas, psicológicas e sociais. É um período caracterizado por conflitos, crises e sentimentos de indefinição, insegurança, necessárias à busca de identidade e liberdade. ${ }^{2}$

Além disso, acontece uma mudança na percepção acerca da imagem que tinham dos pais e mães, que passam a ser alvo de críticas e questionamentos, surgindo com isso a necessidade de uma busca de outros atores sociais, com os quais se identifiquem, fora do âmbito familiar. Nesse momento, o grupo de pares é essencial para o adolescente, sendo que pode haver a aceitação ou rejeição de alguém pelo fato de não corresponder à idealização dos demais. ${ }^{3}$

Essa tendência grupal induz muitos jovens a assumirem comportamentos para os quais não estão preparados, como experimentar drogas, iniciar relacionamento sexual precocemente, entre outros. Na ansiedade de viver tudo rápido e intensamente, acaba não havendo espaço para a reflexão e/ ou julgamento. As vivências da sexualidade aumentam a vulnerabilidade para a AIDS e outras doenças sexualmente transmissíveis, a gravidez na adolescência e o aborto, que podem comprometer o projeto de vida ou até a própria vida do adolescente.

Além disso, a dependência comum na infância cede espaço a uma confusão de papeis, pois o adolescente, não sendo mais criança e não sendo ainda adulto, tem dificuldade em se definir como individuo, em assumir seu papel social e suas novas responsabilidades, inclusive com o autocuidado.

Nesse contexto, adolescentes tornam-se mais vulneráveis, o que torna urgente a implementação de propostas de prevenção de doenças e promoção de saúde. Nessa etapa da vida, risco e vulnerabilidade estão atrelados às características próprias do desenvolvimento psicoemocional, como o sentimento de imunidade, a onipotência, o desejo de experimentar coisas novas; por outro lado, a timidez e a baixa autoestima podem torná-lo potencialmente frágil, levando-o à vinculação com soluções externas inadequadas para os seus problemas como o uso de drogas.

Outra característica desta fase é a tendência em seguir padrões previamente estabelecidos, principalmente pela mídia. Tais padrões induzem a identificação com personagens, como os modelos de beleza e de saúde, que muitas das vezes são incompatíveis com suas condições socioeconômicas ou com sua fase de crescimento, ocasionando transtornos alimentares, deficiências nutricionais, sentimentos de frustração e alterações na imagem corporal.

$\mathrm{Na}$ atualidade, a adolescência tem sido foco de inúmeras pesquisas, por meio das quais o número crescente de casos de DSTs/AIDS, gravidez, suicídio e acidentes vêm ganhando visibilidade. Assim, é possível identificar a importância e necessidade da abordagem do tema sexualidade com esta população. Nesse sentido, vislumbra-se a escola como um local de promoção de saúde; nela as oportunidades de "trocas" por meio do convivio social são facilitadas pelo grande tempo de permanência de estudantes. ${ }^{4}$

Além disso, a escola é também um espaço privilegiado para a promoção de saúde em um enfoque ampliado, na perspectiva de construção de cidadania e envolvimento dos diversos atores que compõem este universo: adolescentes, estudantes, profissionais de educação, familiares, lideres comunitários e profissionais de saúde. ${ }^{5} \mathrm{~A}$ discussão sobre a inclusão do tema "sexualidade" no currículo das escolas de ensino fundamental e médio vem se intensificando desde a década de 70. Porém registros demonstram que em 1920 já havia tais discussões e trabalhos em ambiente escolar, mas foi na década de 80 que ganharam maior visibilidade. No inicio, trabalhava-se a sexualidade não porque se acreditava ser esta importante para o desenvolvimento integral do indivíduo, mas pela preocupação de pais, mães e educadores com o aumento do número de adolescentes grávidas e com AIDS. Hoje se sabe que o entendimento biológico, apesar de importante, não é suficiente para trabalhar orientação sexual nas escolas. É preciso levar em consideração aspectos emocionais, socioculturais, históricos, entre outros.

No Brasil, em 1998, o espaço para a inclusão destes temas foi oficialmente aberto com a implantação dos Parâmetros Curriculares Nacionais (PCNs), tendo como objetivo "promover reflexões e discussões de técnicos, professores, equipes pedagógicas, bem como de pais e responsáveis, com a finalidade de sistematizar a ação pedagógica da escola no trato de questões da sexualidade" 6:287.

$\mathrm{Na}$ atualidade, o número crescente de casos de gravidez na adolescência e de abuso sexual, bem como 0 aumento de doenças sexualmente transmissíveis e de abortos, demonstra a necessidade de discutir abertamente 0 assunto. Nesse contexto é que se ressalta a importância da implantação de projetos de orientação sexual nas escolas, contemplando o desenvolvimento global do ser humano.

Porém, diante desse cenário, não se pode esquecer que a família tem grande influência na formação de adolescentes, 
pois a sexualidade é primeiramente abordada no espaço privado, por meio das relações e comportamentos familiares. Assim, de forma explícita ou implícita, são transmitidos os valores que cada família adota como seus e espera que as crianças e adolescentes assumam.

0 projeto "Saúde e Prevenção nas Escolas" (SPE) é um exemplo desta prática; desenvolvido pela parceria entre os Ministérios da Saúde, Ministério da Educação, Organização das Nações Unidas para a Educação, a Ciência e a Cultura (UNESCO), Fundo das Nações Unidas para a Infância (UNICEF) e Fundo de Populações das Nações Unidas (UNFPA), representa um marco na integração saúde-educação e destaca a escola como espaço institucional privilegiado para a articulação das políticas voltadas para adolescentes e jovens. ${ }^{1}$

O objetivo central do SPE é a promoção da saúde sexual e reprodutiva, visando reduzir a vulnerabilidade de adolescentes e jovens às DSTs, à infecção pelo HIV e a gravidez, por meio de ações nas escolas e nas unidades básicas de saúde. ${ }^{1}$ Construir espaços de diálogo entre adolescentes, professores, profissionais de saúde e comunidade é um importante dispositivo para construir resposta social com vistas à superação das relações de vulnerabilidade entre adolescentes.

Assim, percebe-se que a escola, ao assumir em seu Projeto Político Pedagógico o compromisso com a orientação sexual, poderá ser capaz de contribuir para que crianças e adolescentes desenvolvam a comunicação nas relações interpessoais, elaborem valores a partir do pensamento crítico, compreendam o próprio compor tamento e tomem decisões responsáveis a respeito de sua vida sexual. ${ }^{10}$

A educação para a sexualidade deve considerar também que, para o individuo viver em plenitude no mundo que o cerca, é preciso estar sensibilizado para respeitar a si mesmo e aos outros, saber relacionar-se, ter responsabilidade, crer na vida e procurar vivê-la com prazer, conhecendo seus próprios deveres e direitos, inclusive o de ser feliz.

Nesta perspectiva, o presente estudo foi realizado com os objetivos de conhecer a percepção dos adolescentes acerca das ações de orientação sexual realizadas em uma escola do interior do Rio Grande do Sul e identificar fragilidades e potencialidades das ações, visando o fortalecimento do projeto Saúde e Prevenção nas Escolas (SPE).

\section{CARACTERIZAÇÃO DA PRÁTICA EDUCATIVA REALIZADA NO PROJ ETO SPE}

A escola em que se realizou orientação sexual de adolescentes, por meio do projeto Saúde e Prevenção nas Escolas, possui aproximadamente 100 professores, 19 funcionários e 1.800 estudantes, da pré-escola à terceira série do ensino médio. Docentes do curso de enfermagem e a direção da escola definiram que, no segundo semestre de 2007, estudantes do ensino médio participariam do projeto. $\mathrm{Na}$ ocasião havia duas turmas de primeira série, duas de segunda e duas de terceira. Cada turma tinha, em média, 35 estudantes.

Antes de se iniciar a prática educativa na escola, realizou-se a capacitação dos 27 acadêmicos, matriculados na disciplina de Prática de Assistência de Enfermagem à Criança e ao Adolescente. Essa etapa foi realizada nas dependências do Departamento de Enfermagem da FURG. Durante as trinta horas da capacitação, além de aspectos teóricos, desenvolveram-se oficinas de sensibilização e discutiram-se dinâmicas de trabalho. A segunda etapa foi realizada junto aos adolescentes, em quatro encontros semanais, de aproximadamente duas horas cada. Cada grupo de quatro ou cinco acadêmicos assumia uma turma de adolescentes realizando na íntegra os quatro encontros que foram desenvolvidos na própria sala de aula. No primeiro, os objetivos foram: criar um clima de confiança e diagnosticar os anseios, dúvidas, certezas e preconceitos da turma. Para tanto, os adolescentes, divididos em grupos, discutiam amplamente e completavam a seguinte a sentença: "Para ter uma adolescência saudável, jovens precisam discutir sobre"...

A seguir, cada grupo apresentava à turma seus resultados. Após as apresentações, selecionavam-se os aspectos que seriam discutidos nos três encontros subseqüentes. Procurava-se contemplar todos os temas elencados, agrupando-os por afinidade. Entre os assuntos apontados surgiam dúvidas sobre tamanho do pênis, virgindade, idade "correta" para iniciação sexual, pílula do dia seguinte, uso de preservativo masculino (a maior parte desconhecia o preservativo feminino), DSTs e AIDS, influência da família na vida de jovens, bulimia e anorexia, uso de anabolizantes, entre outros.

Nos demais encontros, além de discutir os temas elencados, procurou-se incitar o gosto pelo autocuidado, a necessidade de perceber as próprias vulnerabilidades e de assumir responsabilidade pelas próprias escolhas. Para tanto, de forma descontraída, jogos, brincadeiras, dramatizações, discussão de textos, filmes e oficinas foram realizados. Houve situações em que os adolescentes abdicavam do recreio para dar continuidade às discussões.

Concluído o trabalho em uma turma, os acadêmicos assumiam outra, de forma que cada grupo trabalhava com pelo menos duas turmas. Com isso era possível verificar 0 aprimoramento na abordagem e desempenho. A totalidade dos encontros era assessorada pelas duas docentes da disciplina 
que participavam ativamente das discussões. Ao término de cada encontro, discentes e docentes avaliavam o trabalho individual e coletivo, com vistas a aprimorar o processo educativo. Além disso, permaneciam disponíveis para Consulta de Enfermagem e encaminhamentos de adolescentes à ginecologista, quando necessário.

\section{METODOLOGIA}

Para o presente estudo, optou-se pela pesquisa qualitativa, pois esta se responsabiliza por questões muito particulares, preocupando-se com um nível de realidade que não pode ser quantificado.?

Os sujeitos foram adolescentes que participaram da ação educativa promovida pelo SPE e aceitaram, por meio da assinatura, juntamente com os responsáveis legais, do Termo de Consentimento Livre e Esclarecido.

A coleta de dados ocorreu no mês de agosto de 2008, na sala do Serviço de Orientação Educacional (SOE) da escola, e foi realizada por meio de entrevistas semiestruturadas, gravadas e transcritas na íntegra, realizadas em horário e data combinados previamente. 0 critério para encerramento das entrevistas foi a saturação dos dados, o que começou a acontecer aproximadamente na oitava entrevista, porém as demais foram realizadas, pois já haviam sido agendadas.

A pesquisa, por envolver seres humanos, foi submetida à apreciação do comitê de ética e pesquisa na área da saúde da FURG, protocolada sob número 23116.003174/2008-98 e aprovada por meio do parecer número 84/2008.

Para assegurar o anonimato, na apresentação dos resultados, utilizou-se a letra $E$ (entrevistado) acrescida do número correspondente à sequência de entrevistas (1, 2, etc.) e das letras M ou F para designar o sexo.

Utilizou-se a análise de conteúdo na modalidade temática, como recurso analítico. A operacionalização dessa fase foi construída a partir das etapas de pré-análise, exploração do material, tratamento dos resultados obtidos e interpretação, durante as quais se elegeram as categorias analíticas, que nor tearam a interpretação dos resultados. ${ }^{7}$

\section{RESULTADO E DISCUSÃO}

Os resultados deste estudo são apresentados e discutidos em duas etapas. Na primeira, procurou-se delinear o perfil dos entrevistados; na segunda, conhecer a percepção de adolescentes acerca das ações de orientação sexual realizadas na escola.
No que se refere ao perfil, dos 15 adolescentes que aceitaram colaborar com a pesquisa, nove eram do sexo masculino e seis do feminino. A idade variou de 15 a 17 anos, todos eram estudantes do segundo ano do ensino médio e nenhum trabalhava.

A partir dos depoimentos foram construídas quatro categorias, quais sejam, o papel da família: 0 ideal $\times$ o real; orientação sexual na escola: uma oportunidade a mais de informação para adolescentes; metodologia participativa: "um jeito de fazer"; e, amigos como fonte de informação, de mero receptores a multiplicadores.

\section{0 papel da família: 0 ideal $\times 0$ real}

0 grupo familiar exerce um papel fundamental na formação de crianças e jovens, sendo importante na determinação e organização da personalidade, além de influenciar significativamente no comportamento individual por meio das ações e medidas educativas tomadas. Assim, podemos dizer que a família é responsável pelo processo de socialização primária e, com isso, tem influência nas questões sexuais desenvolvidas e apreendidas ao longo do tempo. Para os informantes deste estudo, o papel ideal da família é de orientar, ensinar, dar segurança e apoio, como pode ser visto nas falas a seguir:

[...] eu acho que é aconselhar porquejá passaram por tudo que a gente está passando e eles sabem muito mais que a gente. Então é como se fosse uma força sabe... uma segurança para nós, [...] (E1F).

[...] o principal papel da familia é tentar incentivar o máximo os jovens. A família é um grande apoio[...](E4M).

Em contrapartida ao considerado ideal pelos estudante, emergem das falas o que eles realmente vivenciam no seu diadia, que é a dificuldade ou ausência de diálogo familiar:

[...] é uma coisa difícil! Porque é difícil a gente

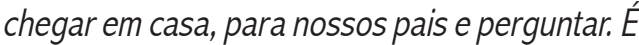
muito mais fácil para a gente procurar uma pessoa mais velha, dentro do nosso circulo de amizade[...](E1F).

[...] a maioria não incentiva. A maioria não fala nada $[\ldots]$ (E3M). 
Os pais eas mães sentem dificuldade em abordar as questões de sexualidade junto aos filhos não só por constrangimento, mas também por medo que o diálogo franco e aberto possa indicar aos adolescentes que já estão prontos para iniciar a vida sexual. ${ }^{8}$ Esta dificuldade ou ausência de diálogo está muitas vezes associada à vergonha, tanto dos pais e mães, como dos filhos:

\section{[...] os pais têm vergonha e os filhos também [...] (E12M).}

Embasados na crença de que a conversa sobre sexualidade pode induzir 0 adolescente a iniciar precocemente a atividade sexual, alguns pais e mães procuram silenciar sobre o assunto. Além disso, não se pode deixar de salientar que existem as influências culturais, as crenças e os costumes que permeiam o contexto de vida das pessoas e influenciam na forma como elas se comportam. Além do mais, muitos adultos de hoje não vivenciaram o diálogo com suas famílias, o que pode influenciar em suas ações e nas dificuldades com seus filhos. ${ }^{9}$

Foi possível identificar que a maioria realmente não tem o diálogo em casa e a vergonha é apontada como um dos motivos tanto por parte dos pais e mães como dos adolescentes.

Assim, o diálogo no ambiente familiar é muito restrito. Na maioria das vezes não existe uma abertura para conversar sobre questões pessoais íntimas. Ainda, a dificuldade em procurar os pais ou mães para esclarecer dúvidas sobre assuntos relacionados à sexualidade pode estar vinculada ao medo de sofrer represálias.

Orientação sexual na escola: uma oportunidade a mais de informação para adolescentes

Vivencia-se atualmente a era do "show do sexo", na qual a erotização invade as casas através de jornais, revistas, rádio, internet e, principalmente, da televisão. Muitas vezes influenciadas pelos ídolos, as crianças estão cada vez mais erotizadas, e adolescentes acabam iniciando a vida sexual cada vez mais cedo, geralmente de forma desprotegida, o que resulta, em muitas ocasiões, na gravidez de garotas recém-saídas da infância.

Por todos esses motivos, as ações educativas direcionadas a adolescentes devem contemplar a saúde sexual e reprodutiva, incluindo as dúvidas, medos e preconceitos, além de considerar o contexto sociocultural, pois as estratégias para serem efetivas devem condizer com suas realidades. ${ }^{10}$

Dessa forma, todos os adolescentes, ao serem questionados sobre o que acharam do trabalho de orientação sexual realizado no ambiente escolar, aprovaram a iniciativa e apontaram como uma oportunidade a mais de informação, pois a maioria não tem diálogo em casa, como é possível identificar nas falas a seguir:

Eu acho muito importante porque a maioria não sabe das coisas. Precisamos de informação e na escola a gente tira bastante dúvida e aprende bastante, porque muitos não conversam em casa e na escola é onde tem os adolescentes, então fica mais fácil e a gente aprende junto, tem que acontecer na escola (E1OF).

Nesse sentido, a escola possui um ambiente que proporciona contato com as diferenças sociais e cria condiç̃oes para a produção e acesso a novos saberes. ${ }^{5}$ Os próprios adolescentes declaram que a escola é o lugar ideal. Ali os jovens estão reunidos, ou seja, é um local de grande permanência, onde se sentem à vontade por estarem entre colegas com os quais convivem cotidianamente:

[...] na escola éonde têm os adolescentes..., então fica mais fácil..., e a gente aprende junto...., tem que acontecer na escola! (E10F).

É possivel perceber que além de aprovarem o trabalho de orientação sexual realizado na escola, consideraram que as atividades desenvolvidas foram imprescindíveis para suas vidas, pois contribuíram com seus processos de viver, ampliando 0 conceito de sexualidade que geralmente está atrelado apenas à relação sexual e trazendo novos conhecimentos, o que permitiu o partilhar de experiências e deu subsídios a escolhas responsáveis:

Foi importante, com certeza, porque a gente aprendeu que tem que prevenir ao máximo... Que não pode dar bobeira, e isso vai implicar em tudo na minha vida..., vai mudar meu comportamento e aí vou só melhorar, né? (E13M).

Foi bastante importante porque eu aprendi e a gente jovem precisa de informação. Tinha coisas, não só de sexo..., mas a higiene pessoal... era algo que eu não sabia direito e várias outras coisas..., e aí todas essas coisas vão me ajudar... porque vou aprender a fazer as coisas direito [...] (E9F).

Essas falas mostram como o trabalho de orientação sexual é capaz de promover a saúde, ensinando cuidados básicos que irão implicar no processo de adolescer saudável.

A escola, ao oferecer a orientação sexual, contribui efetivamente para que estudantes desenvolvam a comunicação nas relações interpessoais, façam escolhas conscientes no que 
se refere à atividade sexual e à prevenção de doenças sexualmente transmissíveis, elaborem valores e compreendam o próprio comportamento, tomando decisões responsáveis a respeito de sua vida sexual, agora e no futuro. ${ }^{11}$

Portanto, ao tratar do tema educação sexual, buscase considerar a sexualidade como algo inerente à vida e à saúde, englobando o papel do homem e da mulher, o respeito por si e pelo outro, as discriminações e os estereótipos atribuídos e vivenciados em seus relacionamentos, questões atuais e preocupantes. Todos esses fatores mostram uma necessidade cada vez maior da inclusão destas temáticas no currículo escolar.

\section{Metodologia participativa: "um jeito de fazer"}

A metodologia participativa é um "jeito de fazer" no qual a pessoa participa do processo de construção do conhecimento, buscando trabalhar de maneira conjunta, na qual os adolescentes escolhem os temas a serem debatidos, explicitando suas necessidades e possibilitando a criação de um espaço de trocas e descobertas.

Foi possível identificar na fala da adolescente que, com esse tipo de metodologia de ensino, foi mais fácil e descontraído aprender:

Eu acho que as brincadeiras ajudam porque foi muito divertido. Foi interessante porque vocês fazendo esse tipo de brincadeira é o que a gente gosta de fazer..., tipo brincadeira essas coisas assim... então é uma coisa que atrai. A gente se interessa pelo que vocês estão falando..., se vocês fossem lá para frente e só falar... falar... e falar... vocês iam sair dali e a gente ia ficar reclamando. A gente ia perder uma chance, porque a gente não ia levar nada daquilo. Vocês brincando, interagindo com a gente, fica mais fácil de aprender [...] (E1F).

A metodologia participativa é um espaço dinâmico na qual a participação e a reflexão de todos são requisitos fundamentais para compreensão dos conteúdos e para construção do conhecimento. A linguagem utilizada para realização de orientação sexual com adolescentes adaptada às suas vivências do dia-a-dia também é algo relevante de ser considerado, pois aproximou os educadores dos jovens, tornando o entendimento e a interação mais fáceis, proporcionando maior "absorção" das informações, como pode ser visto nas falas a seguir:
[...] foi bem descontraído e isso ajuda a gente a entender melhor. A linguagem foi boa, porque vocês não falavam assim complicado [...] (E3M).

Eu gostei do jeito que foi..., várias brincadeiras, 0 que ajuda a gente a pegar a informação... e teve uma linguagem boa [...] (E5M).

É preciso utilizar uma linguagem clara com o mínimo possível de termos científicos, usando até mesmo expressões do cotidiano dos adolescentes para enfocar assuntos que englobam a sexualidade. Isso proporciona uma maior aproximação com esses jovens e também uma melhor compreensão das informações recebidas. ${ }^{12}$

Uma das formas importantes de adaptar as intervenções ao contexto sociocultural dos adolescentes é a incorporação de sua linguagem. A análise de "metáforas" que eles utilizam ao falarem sobre sexo pode proporcionar pontos valiosos na compreensão das formas como entendem 0 comportamento sexual e os relacionamentos sexuais. ${ }^{13}$

A metodologia participativa também é mais adequada inclusive para diminuir a vergonha ou timidez dos jovens, podendo, assim, contribuir para um melhor aprendizado e esclarecimento de dúvidas:

Foi bem legal porque a gente aprendeu de um jeito bom..., brincando! E isso ajuda um monte! A gente aprende e não fica chato..., assim a gente participa..., pois às vezes a gente fica com um pouco de vergonha [...] (E1OF).

\section{[...] o jeito como foi feito ajuda a tirar a timidez e a gente participa... A gente pega melhor as informações porque é muito melhor aprender brincando [...] (E12M).}

Cabe enfatizar que não é com terrorismo nem com informações isoladas que se pode mudar a realidade de adolescentes em relação às suas práticas, sobretudo no que diz respeito ao cuidado de si e das relações afetivas sexuais. Sendo assim, é notória a necessidade de dinâmicas de grupo no processo de formação de agentes sociais dentro de uma perspectiva metodológica participativa de construção coletiva de saberes, visto que os sujeitos integrantes do grupo tornamse parte indispensável desta construção e buscam produzir práticas inovadoras.

É possível perceber que a metodologia participativa desperta 0 interesse e atenção dos adolescentes; eles) identificam esse tipo de metodologia pela palavra "brincadeira", 
ou seja, aprender de maneira descontraída, na qual é permitida uma relação aberta e espontânea entre os membros que participam das dinâmicas de grupo. Esse tipo de metodologia permite aos adolescentes participarem da construção do conhecimento e com isso se sentirem sujeitos no projeto de orientação sexual, no qual podem expor ideias e refletir sobre como ter um comportamento responsável diante da sua saúde física e mental, com ênfase na saúde sexual e reprodutiva.

Amigos como fonte de informação, de mero receptores a multiplicadores

Durante a adolescência é comum um afastamento da família, sendo assim os adolescentes passam a conviver mais com os amigos ou grupos de amigos, com os quais se identificam. Estespassam a ser confidentes e cúmplices dessa fase da vida. Entre eles, as conversas se tornam mais fáceis, devido ao fato de estarem passando por momentos parecidos e terem dúvidas semelhantes em muitas situações novas, o que torna a conversa espontânea e sem constrangimento.

0 grupo social exerce papel significativo no processo de formação e desenvolvimento do adolescente. Muitas atitudes e modos de perceber o mundo, o "outro" e a si mesmo são influenciados pelo grupo, no qual o adolescente está inserido e com o qual se identifica. Torna-se, por si só, um possível multiplicador de ideias, valores e concepções, podendo ser um recurso valioso no processo educativo. Nas falas a seguir é possível identificar que os jovens procuram outros jovens para conversar:

[...] é muito mais fácil para a gente procurar uma pessoa mais velha dentro do nosso circulo de amizade e perguntar [...] (E1F).

\section{[...] muitos que não falam com os pais falam com} amigos [...] (E7M)

É possível perceber que os adolescentes se sentem mais a vontade ao conversar com amigos e, muitas vezes, diante da falta de diálogo em casa, colegas passam a ser a fonte de informação mais acessível. Diante desse contexto fica evidente que os próprios jovens podem contribuir com o processo de viver saudável de seus colegas, "pois é indispensável reconhecer que o jovem é detentor de saberes e práticas que devem ser respeitadas e valorizadas na construção do conhecimento"1:15. Esta contribuição dos jovens pode se tornar uma realidade quando se desenvolvem projetos com a intenção de formar adolescentes multiplicadores, que ao mesmo tempo são beneficiários e protagonistas da ação.

A formação de "Adolescentes Multiplicadores" no Brasil é uma diretriz dos Ministérios da Saúde e da Educação, que é colocada em prática através do Projeto Saúde e Prevenção nas Escolas (SPE). Com esta formação especíica, é possível que os adolescentes adquiram e ampliem seu repertório interativo, aumentando assim sua capacidade de refletir de forma ativa e construtiva em seu contexto escolar e sociocomunitário, sendo então Protagonistas Juvenis. ${ }^{1}$

Os Projetos de protagonismo juvenil podem abordar não somente questões que envolvem a orientação sexual, mas também podem promover o engajamento de jovens em ações voluntárias em benefício da comunidade, são ações de cidadania que trazem oportunidades para a ampliação do conhecimento dos estudantes sobre a realidade social .

Hoje em dia, com as crescentes situações de risco a qual os jovens estão expostos e especialmente vulneráveis, se torna fundamental a busca de novas tecnologias, ou seja, é buscando novas maneiras de agir, argumentar e ousar que será possível contribuir para que os adolescentes tenham maiores possibilidades de tornarem-se cidadãos capazes de viver a vida de forma saudável, aproveitando seus prazeres de forma responsável e consciente.

\section{CONSIDERAÇÕES FINAIS}

A realização deste estudo permitiu conhecer a percepção dos adolescentes a respeito do projeto de orientação sexual realizado na escola, bem como reconhecer como as ações desenvolvidas implicaram no seu processo de viver. Sendo assim, ao analisar os dados deste estudo, foi possível identificar que os adolescentes aprovam esse tipo de trabalho sendo, a maioria relatou a importância do projeto para a sua vida, principalmente devido à ausência de dialogo com a família. Apesar desta realidade, acreditam que a família exerça um papel fundamental em seu processo de formação.

Além disso, foi possível identificar também potencialidades do projeto de orientação sexual na escola, como a metodologia participativa utilizada na realização das atividades com os adolescentes, a qual é capaz de promover um clima de trabalho acolhedor e produtivo, proporcionando maior envolvimento e aprendizado.

Ainda, percebeu-se que a busca de novas estratégias para diminuir a vulnerabilidade nessa fase da vida é um instrumento imprescindível para realização de projetos como o SPE; sendo assim, o protagonismo juvenil vem se mostrando um instrumento eficaz para realização de trabalhos que visam à prevenção de doenças e a promoção da saúde de jovens, ainda mais quando se trata de trabalhos realizados para outros adolescentes, pois, como já foi apresentado, os jovens conversam muito entre eles por se sentirem mais a vontade e 
estarem compartilhando dúvidas e sensações semelhantes dessa etapa da vida.

A escola foi considerada o local ideal para realização de projetos de orientação sexual, pois proporciona um ambiente acolhedor e capaz de trazer conhecimentos que irão implicar no seu processo de viver; portanto, é considerada um espaço institucional privilegiado para a convivência social e estabelecimento de ações que visem à promoção da saúde.

Os trabalhos de orientação sexual realizados tanto por profissionais que atuam na escola como por profissionais da área da saúde são fundamentais para o enfrentamento de problemas sociais individuais e coletivos que afetam os adolescentes. Os projetos político pedagógicos das escolas precisam contemplar esta especificidade, trazendo benefícios para suas vidas, pois estão em uma fase peculiar de desenvolvimento, tanto emocional quanto físico e social.

Assim, os programas orientação sexual desenvolvidos nas escolas não podem limitar-se à prevenção de DSTs e gravidez; eles precisam ser abrangentes, ou seja, é indispensável que tragam para a discussão aspectos gerais da sexualidade humana, que constituem a base para uma vida sexual saudável e prazerosa. Ainda, é imprescindível salientar que os adolescentes são detentores do poder de escolha, mas precisam estar cientes de suas responsabilidades, pois as consequências de seus atos poderão interferir em todo o seu projeto de vida.

\section{REFERÊNCIAS}

1.Ministério da Saúde (BR). Saúde e prevenção nas escolas: guia para a formação de profissionais de saúde e de educação. Brasília (DF);2006.

2.Saito IM. Adolescência, cultura, vulnerabilidade e risco. Pediatr [periódico na internet]. 2000; [citado 12 mar 2008]. 22(3): 21719. Disponível em:www.pediatriasaopaulo.usp.br/upload/html/473/ body/01.htm.

3. Feijó RB, Oliveira EA. Comportamento de risco na adolescência. J Pediatr [periódico na internet]. 2001; [citado 03 mar 2008]. 77(supl 2): 125-134. Disponível em:

http://www.medicina.ufba.br/educacao_medica/graduacao/ dep_pediatria/disc_pediatria/disc_prev_social/roteiros/ adolescencia/comp\%20de\%20risco.pdf

4. Beserra EP, Araújo MFM, Barroso MGT. Promoção da saúde em doenças transmissíveis: uma investigação entre adolescentes. Acta Paul. Enferm [periódico na internet]. 2006; [citado 07 maio 2008]. 19(4): 402-07. Disponível em: http://www.scielo.br/pdf/ape/v19n4/ v19n4a06.pdf
5.Ramos FRS. Adolescer: compreender, atuar, acolher. Projeto Acolher: um encontro da Enfermagem com o adolescente brasileiro. Brasília(DF): ABEn; 2001.

6 Ministério da Educação e do Desporto (BR). Parâmetros curriculares nacionais: terceiro e quarto ciclos. Brasília (DF); 1998.

7.Minayo MCS. 0 desafio do conhecimento: pesquisa qualitativa em saúde. 10ª ed. São Paulo(SP): Hucitec; 2007.

8.Cano MAT, Ferriani MGC. A família frente à sexualidade dos adolescentes. Acta Paul Enferm [periódico na internet]. 2000; [citado 07 maio 2008 ]. 13(1): 38-46. Disponivel em:http://www.unifesp.br/ denf/acta/2000/13_1/pdf/art4.pdf

9.Sousa LB, Fernandes JFP, Barroso, MGT. Sexualidade na adolescência: análise da influência de fatores presentes no contexto familiar. Acta Paul Enferm [periódico na internet]. 2006; [citado 07 mar 2008]. 19( 4): 408-13.

Disponível em: http://www.scielo.br/pdf/ape/v19n4/v19n4a07.pdf

10 Beserra EP, Pinheiro PNC, Barroso MGT. Ação educativa do enfemeiro na prevenção de doenças sexualmente transmissíveis: uma investigação a partir das adolescentes. Esc Anna Nery Rev Enferm 2008 set; $12(3)$ : 522-28.

11.Azevedo SPM, Moreira AAJ, Corforto ATM. Educação sexual ou orientação sexual? Disponível em

<boasaude. uol.com. br/lib/

ShowDoc.cfm?LibDocID=3745\&ReturnCatID=1802 - 36k>

Acessado em 19/02/2008.

12.Pereira ED. Adolescência: um jeito de fazer. Rev UFG [periódico na internet]. 2004 jun; [citado 2008 ago 02]; 6(1). Disponivel em: www.proec.ufg.br/revista_ufg/juventude/adoles.html

13. Undie CC, Crichton J, Zulu E. Falar sobre o sexo: o uso da linguagem juvenil na educação sexual. [periódico na internet]. 2007 mar; [citado 10 set 2008]. Disponível em:

http://www.tropeninstituut.nl/net/KIT_Publicaties_output/ ShowFile2.aspx?e=1377 